\title{
A modalidade volitiva no discurso de posse de Jair Bolsonaro
}

\author{
The volitive modality in the Jair Bolsonaro's speech of possession
}

André Silva Oliveira*

\begin{abstract}
RESUMO: O presente trabalho se pro-
ABSTRACT: The present paper aims to põe a descrever e analisar a modalidade volitiva, que se refere, segundo a Gramática Discursivo-Funcional (GDF) de Hengeveld e Mackenzie (2008), ao que é (in)desejável, tendo por base dois parâmetros: o domínio semântico e a orientação modal. Para isso, foi escolhido o discurso de posse de Jair Bolsonaro, que foi proferido no dia $1^{\circ}$ de janeiro de 2019 e disponibilizado on-line. A partir da descrição e da análise qualitativa empreendida, verificamos que a modalidade volitiva se manifesta, no discurso de posse, com orientação para o participante, haja vista que o falante (presidente empossado) tende a expressar suas pretensões em termos de ações políticas em seu mandato que se inicia, envolvendo-se com a performatização do evento sobre o qual incide a volição. Além disso, a modalidade volitiva tende a estar rela-cionada com a não controlabilidade [controle] do estado-de-coisas, tendo um sujeito animado [+ humano] como fonte da atitude modal, podendo este ser especificado ou não no discurso [ \pm determinado]. Em relação ao tempo e ao modo, o presidente eleito prefere empregar o presente do modo indicativo, describe and analyze the volitive modality, which refers to the Functional Discourse Grammar (FDG) of Hengeveld and Mackenzie (2008), to what is (in) desirable, from two parameters, the domain semantic and the modal orientation. For this, was chosen for Jair Bolsonaro's speech of possession, which was delivered on January 1, 2019 and made available online. From the description and qualitative analysis undertaken, we verified that the volitive modality manifests itself in the inaugural speech, with orientation towards the Participant, given that the speaker (president-in-office) tends to express his pretensions in terms of political actions in his inauguration, getting involved with the performatization of the event on which volition affects. In addition, the volitive modality tends to be related to the non-controllability of the state-of-affairs, having an animated subject [+ human] as the source of the modal attitude, which may or may not be specified in the discourse $[ \pm$ determined]. In relation to tense and mode, the president-elect prefers to use the present in the indicative way, the volitional now of enunciation,
\end{abstract}

\footnotetext{
* Mestre em Linguística. Doutorando em Linguística pelo Programa de Pós-Graduação em Linguística da Universidade Federal do Ceará (PPGL/UFC). ORCID: http://orcid.org/0000-0003-3448-0658. andrethtzn@gmail.com
} 


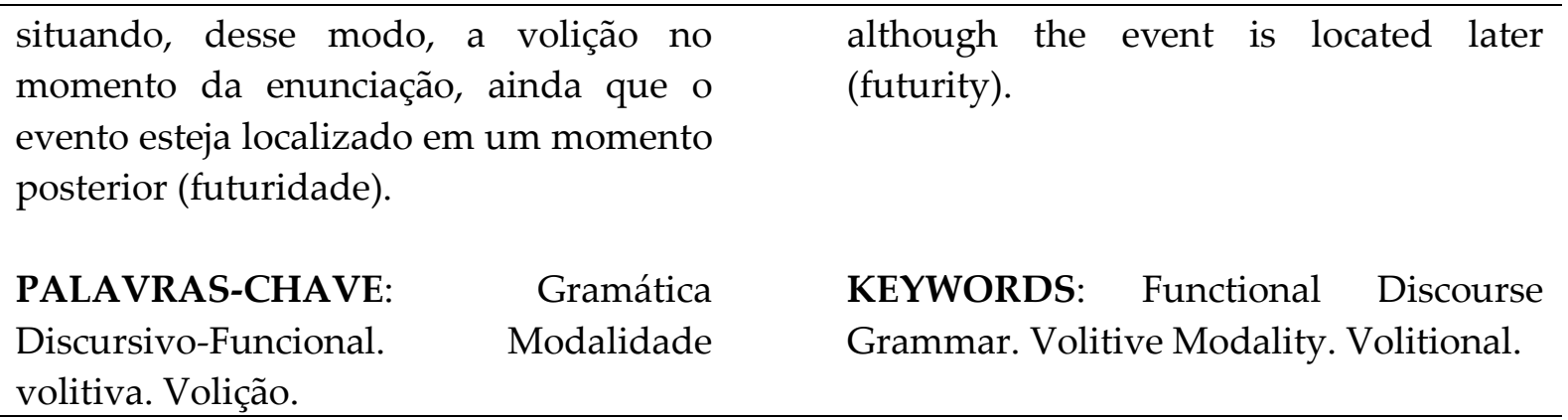

\section{Introdução}

A modalidade volitiva refere-se, de acordo com Hengeveld e Mackenzie (2008), ao que é (in)desejável. Nesse sentido, essa categoria de modalidade está situada no eixo da volição, sendo a ela atribuídos, conforme Oliveira (2017), os seguintes valores modais: desideração, optação, intenção e exortação. Para verificar os aspectos semânticofuncionais da modalidade volitiva, recorremos à Gramática Discursivo-Funcional (GDF), modelo esse de gramática funcional, hierarquicamente estruturado, que entende que a pragmática (nível interpessoal) condiciona os aspectos semânticos (nível representacional) das unidades linguísticas, que, por sua vez, influenciam na marcação morfossintática e fonológica (respectivamente, os níveis morfossintático e fonológico) dessas mesmas unidades.

Pautando-nos na GDF, descreveremos e analisaremos, qualitativamente, a modalidade volitiva a partir de dois parâmetros: o domínio semântico e a orientação modal, como é previsto tanto em Hengeveld (2004) quanto em Hengeveld e Mackenzie (2008). O domínio semântico trata do tipo de avaliação que se faz do enunciado modalizado, dividindo a categoria modalidade em cinco: facultativa, epistêmica, evidencial, deôntica e volitiva. Por sua vez, a orientação modal se refere à parte do enunciado que é modalizada, podendo a modalidade estar orientada para o participante, o evento ou a proposição. Para isso, selecionamos o discurso de posse para a descrição e análise da modalidade volitiva. 
Para esta pesquisa, nossa posição é a de que o discurso de posse, como um texto de caráter argumentativo-expositivo, propicia a manifestação da modalidade volitiva, haja vista que o presidente empossado poderia expressar seus desejos e intenções acerca de suas futuras ações políticas como chefe de Estado ou fazer apreciações sobre aquilo que ele espera (no sentido volitivo, de expectação em relação a um dado evento sobre o qual incide a volição) de apoio dos demais segmentos que compõem o quadro político de seu país. Desse modo, selecionamos o discurso de posse do presidente eleito, Jair Bolsonaro, que foi proferido no dia 1/1/2019 e disponibilizado on-line.

Para melhor organização deste trabalho, optamos, na primeira parte, por apresentar, sucintamente, os aspectos gerais acerca do modelo teórico da GDF. Em seguida, discorreremos sobre a categoria modalidade volitiva a partir da perspectiva do arcabouço teórico da GDF. Na sequência, abordaremos os aspectos metodológicos da pesquisa, bem como faremos a apreciação e delimitação das categorias de análise. Posteriormente, exporemos a descrição e a análise qualitativas empreendidas sobre a modalidade volitiva no corpus selecionado, no caso, o discurso de posse de Jair Bolsonaro. Por fim, apresentaremos as considerações finais acerca dos resultados obtidos neste trabalho e as referências.

\section{Pressupostos teóricos}

A Gramática Discursivo-Funcional (GDF) de Hengeveld e Mackenzie (2008) ${ }^{1}$ foi desenvolvida a partir do entendimento de que as escolhas pragmáticas determinam e influenciam as escolhas semânticas, que, por sua vez, serão codificadas morfossintática

\footnotetext{
${ }^{1}$ A Gramática Discursivo-Funcional (GDF) de Hengeveld e Mackenzie (2008) não é uma gramática funcional do discurso, visto que o termo discursivo não se refere a uma "organização textual" ou a uma "formação ideológica", tratando-se, portanto, da menor unidade comunicável, o ato discursivo, descrito e analisado a partir de um modelo amplo de interação verbal, em que a descrição das expressões linguísticas deriva da situação comunicativa. Para esta pesquisa, o arcabouço teórico da GDF servirnos-á para estudar o modo como as línguas naturais codificam, sistematicamente, as intenções comunicativas do falante, examinando de que modo as atitudes deste são realizadas linguisticamente.
} 
e fonologicamente. Baseando-se no percurso que vai do pragmático ao fonológico, especificamente dentro do componente gramatical, a GDF apresenta uma estrutura rigorosamente top-down, que tem início com a intenção do falante no componente conceitual, passando pelo componente gramatical (que está estruturado em níveis e camadas), interagindo com o componente contextual, até a articulação que se dá no componente de saída.

De maneira muito sucinta, dentro do componente gramatical, são quatro os níveis descritos na GDF: (i) o nível interpessoal, que está relacionado à pragmática e diz respeito à interação estabelecida entre o falante e o ouvinte; (ii) o nível representacional, que se refere à semântica e, portanto, ao significado das unidades linguísticas; (iii) o nível morfossintático, que trata dos aspectos estruturais das unidades linguísticas; e (iv) o nível fonológico, que inclui os aspectos prosódicos e segmentais das unidades linguísticas.

Segundo Hengeveld e Mackenzie (2008), nos níveis interpessoal e representacional ocorre a operação de formulação, que se refere às regras que determinam a constituição das representações tanto pragmáticas quanto semânticas subjacentes e que são válidas em uma dada língua, enquanto a operação de codificação, que ocorre nos níveis morfossintático e fonológico, trata das regras que convertem as representações pragmáticas e semânticas dos níveis mais acima em representações morfossintáticas e fonológicas.

Os componentes que estão fora do componente gramatical, de acordo com os autores, mas que também influenciam nas operações de formulação e codificação que ocorrem dentro do componente gramatical, podem ser assim explicitados: (i) componente conceitual - responsável pelo desenvolvimento tanto da intenção comunicativa do falante que é relevante para o evento de fala quanto das conceitualizações relativas aos eventos extralinguísticos; (ii) componente contextual - contém a descrição do conteúdo e da forma do discurso precedente, bem como do contexto real perceptível por parte 
dos participantes do discurso e das relações sociais entre eles; e (iii) componente de saída - responsável por gerar as expressões linguísticas de diferentes naturezas, podendo ser acústicas, gestuais ou escritas, cuja função básica consiste na tradução da informação dita digital (categorial e com base em oposição) na gramática para uma forma analógica (continuamente variável).

Na Figura 1, podemos visualizar a arquitetura geral do modelo da GDF.

Figura 1: Esquematização geral da GDF de Hengeveld e Mackenzie (2008).

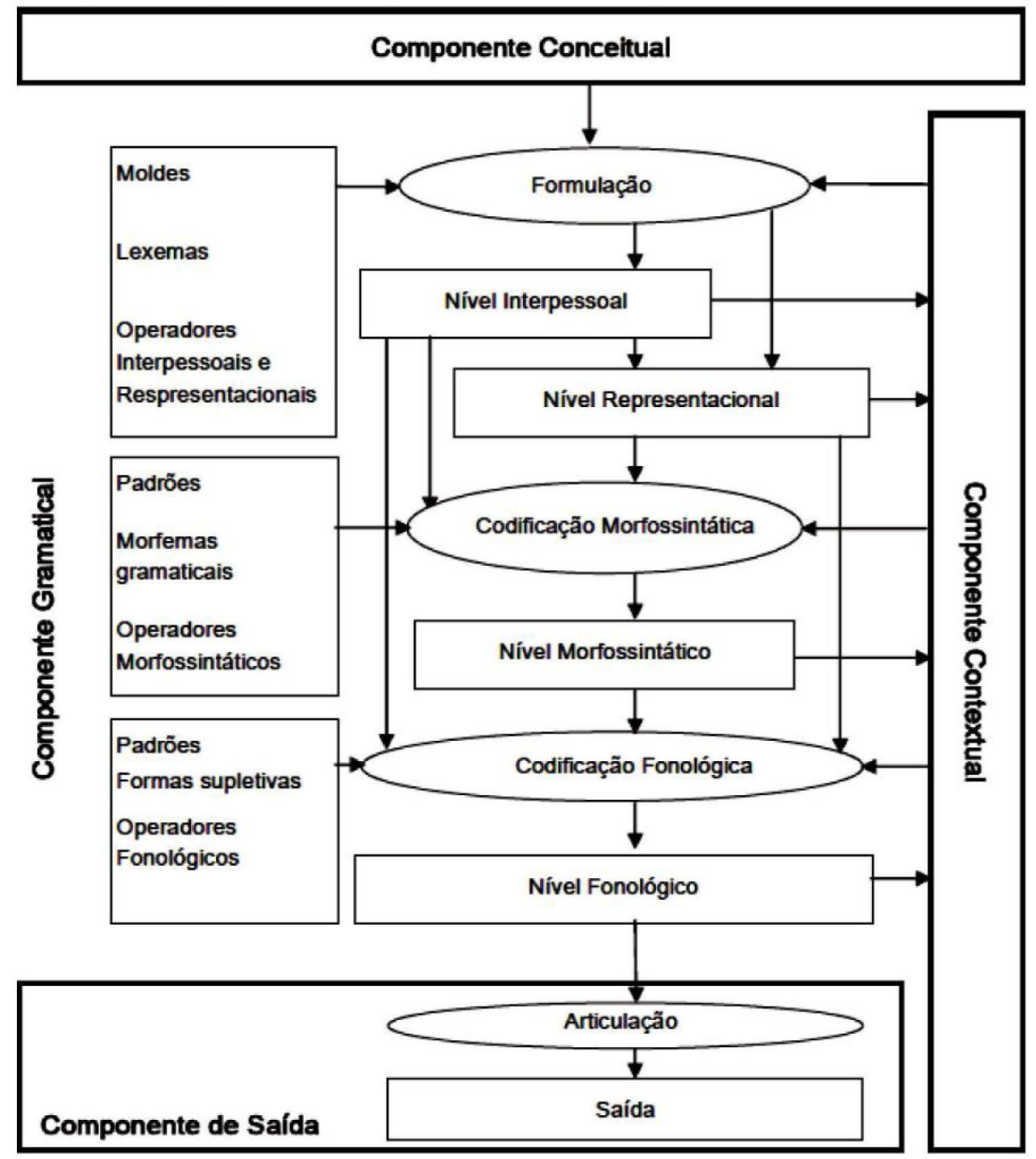

Fonte: Esquema geral da GDF traduzido de Hengeveld e Mackenzie (2008, p. 13). 
No aparato teórico da GDF, conforme os autores, as distinções modais são tratadas, especificamente, dentro do nível representacional que, como citado anteriormente, refere-se aos aspectos semânticos das unidades linguísticas. Nesse nível, as unidades linguísticas são descritas em razão da categoria semântica que designam, podendo ser de quatro tipos: (i) conteúdos proposicionais (p), que podem ser factuais, quando se referem aos conhecimentos e crenças do mundo, ou não factuais, quando se trata de desejos ou expectativas em relação a um mundo imaginário; (ii) episódios (ep), que são conjuntos de estado-de-coisas tematicamente coerentes, já que revelam unidade ou continuidade de tempo (t), localização (l), e indivíduos (x), localizados em um tempo absoluto; (iii) estados-de-coisas (e), que envolvem eventos e estados com localização no tempo e no espaço e que podem ser avaliados em termos de seu estatuto de realidade, podendo ou não ocorrer em um intervalo de tempo relativo; e (iv) propriedades configuracionais (f), que são de natureza composicional, contendo uma combinação de unidades semânticas que não estabelecem uma relação hierárquica entre si.

O tratamento que é dado às modalidades no aparato teórico da GDF está ancorado, basicamente, na categorização que é proposta por Hengeveld (2004), que postula dois parâmetros para a análise da categoria modalidade: a orientação modal, que consiste na parte do enunciado que é modalizada, e o domínio semântico, que diz respeito ao tipo de avaliação que é feita do enunciado modalizado.

Fundamentado no primeiro parâmetro, o autor pondera que as modalidades podem estar orientadas para: (i) o participante, que afeta a parte relacional do enunciado quando expressa por um predicado e diz respeito à relação entre (propriedades de) um participante em um evento e a realização potencial desse evento; (ii) o evento, que diz respeito à parte descritiva de um enunciado e à asseveração objetiva do status de realização do evento; e (iii) a proposição, que está relacionada à parte do enunciado que representa as visões e as crenças do falante e diz respeito à 
especificação do grau de comprometimento do falante em relação à proposição que ele apresenta no enunciado modalizado.

Com base no segundo parâmetro, ainda conforme o autor, as modalidades podem ser: (i) facultativa - relacionada às habilidades intrínsecas ou às adquiridas; (ii) epistêmica - relativa aos conhecimentos de certeza ou dúvida sobre o mundo real; (iii) evidencial - referente à fonte da informação que é apresentada; (iv) deôntica, referente ao que é moral, legal e socialmente aceito; e (v) volitiva - trata do que é (in)desejável.

Especificamente sobre a modalidade volitiva, foco desta pesquisa, Hengeveld e Mackenzie (2008) situam-na no eixo da volição, estando, pois, relacionada ao que é (in)desejável (domínio semântico). Com relação à orientação modal, ainda segundo os autores, a modalidade volitiva pode estar orientada para: (i) o participante, quando se refere ao desejo do participante de se envolver no evento que é designado pelo enunciado modalizado, como no exemplo: Nós queremos partir; ${ }^{2}$ e (ii) o evento, quando há a caracterização de eventos em termos do que é geralmente aceito como (in)desejável, mas sem que haja algum tipo de apreciação por parte do falante, como no exemplo: Seria ruim se eu quebrasse isso. ${ }^{3}$

Sabendo-se que a modalidade volitiva se refere ao que é (in)desejável, e que ao modalizar volitivamente, o falante pode manifestar a pretensão de se envolver em um dado evento por ele desejado ou simplesmente reportar o que é (in)desejável, acreditamos que os discursos de posse podem ser propícios para a manifestação dessa categoria, como veremos na seção seguinte.

\footnotetext{
2 Tradução nossa. O original diz: “We want to leave” (HENGEVELD; MACKENZIE, 2008, p. 213).

${ }^{3}$ Tradução nossa. O original diz: "It would be bad if I broke it" (HENGEVELD; MACKENZIE, 2008, p. 176).
} 


\section{Metodologia}

Para a descrição e análise da modalidade volitiva, recorremos ao discurso de posse de Jair Bolsonaro, que foi proferido no dia 1ำ de janeiro de 2019, dia em que foi empossado para o cargo de presidente da República Federativa do Brasil. O discurso encontra-se disponibilizado no endereço eletrônico: https://bit.ly/2CT8y6r. ${ }^{4}$

De acordo com Leal (2015), o discurso de posse trata de um ato comunicativo que é proferido no dia em que novos líderes, tradicionalmente, assumem uma responsabilidade de maneira oficial, em que a posse é um rito de passagem, uma ruptura, na maioria das vezes, da relação que existia anteriormente à nova gestão. Conforme o autor, os discursos de posse se estruturam em torno de análises da conjuntura do período em que está inserido e das possíveis diretrizes futuras da administração que se inicia, já que o novo líder pode assinalar o que foi relevante ou pouco produtivo em relação à gestão anterior e pontuar suas pretensões (volição) em relação ao que espera realizar em seu mandato. Por isso, ainda segundo o autor, a construção argumentativa dos discursos de posse é "uma rica fonte de análises, tanto pela sua organicidade tácita como pelas representações presentes no texto" (LEAL, 2015, p. 8).

De acordo com Dall' Aglio Hattnher (2009), os discursos de posse são relevantes para a descrição e a análise da categoria modalidade, considerando que as condições de produção desses discursos facilitam a recuperação das intenções (volição) do falante, pois, de alguma forma, remetem à sua ideologia partidária, a seus pontos de vista acerca de temas entendidos como "polêmicos", a outros discursos proferidos anteriormente etc., e à identificação do "grau de tensão" que seu discurso estabelece entre os ouvintes, sejam eles apoiadores ou não dele como chefe do Poder Executivo.

\footnotetext{
${ }^{4}$ Acesso em: 6 jan. 2019.
} 
Dessa forma, acreditamos que o discurso de posse seja relevante para a descrição e a análise da modalidade volitiva em razão dos diferentes efeitos de sentido que a volição pode acarretar ao encadeamento discursivo, já que a volitividade expressa pode tanto sinalizar que o falante aprecia como sendo bom e agradável o estado-de-coisas sobre o qual incide a volição quanto manifestar o que ele espera em termos de ações políticas ou apoio por parte dos parlamentares para seguir seu plano de governo.

No intuito de descrevermos e analisarmos a modalidade volitiva, qualitativamente, no discurso de posse de Jair Bolsonaro, e considerando o que é disposto na GDF e em trabalhos acerca dessa categoria, pautamos algumas categorias de análise assim distribuídas: (i) a orientação modal, que pode ser orientada para o participante ou o evento; (ii) a controlabilidade do estado-de-coisas por parte do falante, em que o falante pode ter controle [+ controle] ou não sobre o estado-de-coisas [- controle] sobre o qual incide a volição; (iii) os traços semânticos do sujeito, que podem ser de animacidade [+ humano] ou [- humano] e tratar de entidades presentes na conversação [+ determinado] ou fazer alusão a entidades genéricas [- determinado]; e (iv) o tempo e modo verbais, em que a modalidade volitiva é expressa pelo falante.

Após dissertarmos acerca da metodologia que será empregada nesta pesquisa, passaremos à seção na qual apresentaremos a descrição e a análise da modalidade volitiva no discurso de posse de Jair Bolsonaro.

\section{Resultados}

Ao observamos o discurso de posse de Jair Bolsonaro tendo por objetivo descrever e analisar a modalidade volitiva com base nos pressupostos teóricos da GDF, percebemos casos de volição que foram expressos por meio de verbos volitivos, tais como querer, desejar, pretender, precisar etc., e o emprego da perífrase ir+infinitivo, na expressão de futuridade (pretensão de realizar algo). De acordo com Felix de Oliveira 
(2016), os verbos volitivos empregados na manifestação da volição apresentam um sujeito como fonte do desejo [+ humano], podendo, morfossintaticamente, vir expressos por meio de um verbo auxiliar (constituindo uma perífrase de infinitivo) ou de um verbo pleno. Vejamos (1) e (2):

(1) "Pretendo partilhar o poder, de forma progressiva, responsável e consciente, de Brasília para o Brasil; do Poder Central para Estados e Municípios".

(2) "Daqui em diante, nos pautaremos pela vontade soberana daqueles brasileiros: que querem boas escolas, capazes de preparar seus filhos para o mercado de trabalho e não para a militância política [...]".

Em (1), o presidente eleito emprega o verbo volitivo pretender em uma construção perifrástica com o verbo no infinitivo, partilhar, para expressar a intenção (volição) que incide sobre o evento, no caso, descentralizar o poder central de Brasília para os demais Estados e Municípios. Em (2), o presidente empossado emprega o verbo volitivo querer em sua forma plena para reportar a volição do participante expresso (aqueles brasileiros) envolvido no evento que integra a predicação, em que a volição incide sobre boas escolas capazes de preparar os filhos para o mercado de trabalho. De acordo com Hengeveld e Mackenzie (2008), em (1) e (2), a modalidade volitiva está orientada para o participante, uma vez que faz menção, respectivamente, ao desejo (intenção) do falante (Jair Bolsonaro) e do participante expresso no enunciado (daqueles brasileiros) de se envolverem no evento que é designado pelo enunciado modalizado.

A orientação modal pode, conforme os autores, indicar o grau de comprometimento do falante em relação ao que ele enuncia, haja vista que: (i) na orientação para o participante, há um maior comprometimento do falante, pois ele manifesta suas volições sobre futuras ações políticas de seu mandato, ou seja, o evento sobre o qual incide a volição trata de algo que por ele é intencionado, podendo incidir no plano performativo, como podemos verificar em (1), ou pode se comprometer, quando reporta a volição de terceiros ao manifestar uma apreciação dos desejos e das 
vontades de outrem em seu discurso, como podemos constatar em (2); e (ii) na orientação para o evento, há um menor comprometimento do falante, já que este apenas reporta o que é desejável, sem que faça uma apreciação do evento sobre o qual incide a volição, como neste exemplo retirado da internet (disponível em https://bit.ly/2N2tXgQ): É desejável que haja um equilíbrio. Mas não tem obrigação de ser de outra Força; ${ }^{5}$ em que o falante apenas reporta o que parece ser desejável em termos da escolha dos ministros que irá compor a nova base dos ministérios do então presidente, Jair Bolsonaro. A leitura volitiva é favorecida pela inexistência de uma regra de conduta que "obrigue" o atual presidente a escolher os ministros de distintas "forças" (no caso, que compõem as Forças Armadas: Exército, Marinha ou Aeronáutica), deslocando o adjetivo em posição predicativa, é desejável, do eixo da conduta (modalidade deôntica) para o eixo da volição (modalidade volitiva). A modalidade volitiva também é asseverada pela negação de obrigação que é reportada pelo falante ( ão tem obrigação de), produzindo, pois, um efeito de sentido de querer-fazer (volição) e não de dever-fazer (obrigação).

Em (1) e (2), constatamos também que a fonte da atitude modal trata de um ser capaz de volição [+ humano], respectivamente: o presidente eleito, que manifesta a intenção (volição) de descentralizar o poder, em que o uso da primeira pessoa do singular, pretendo, revela um comprometimento dele perante os seus ouvintes com aquilo que por ele é volicionado; e aqueles brasileiros, que são reportados pelo novo presidente da República, ao empregar a terceira pessoa do plural, querem, declarando o desejo deles de que haja escolas que preparem seus filhos para o mercado de trabalho. No que tange à especificidade dos sujeitos presentes na conversação, atestamos: em (1), que o sujeito é especificado [+ determinado] na conversação, em questão, o presidente eleito (EU); enquanto, em (2), o sujeito é pouco especificado [determinado], já que não determina que segmentos da sociedade ou tipo de classe

\footnotetext{
${ }^{5}$ Acesso em: 12 fev. 2019.
} 
social "desejam boas escolas para seus filhos", limitando-se, apenas, a referir-se a uma "parcela da população brasileira" (ELES).

De acordo com Gasparini-Bastos (2014), uma característica relevante da modalidade volitiva é a não controlabilidade [- controle] do estado-de-coisas contido na predicação, ou por parte do falante ou do participante expresso no predicado, o que favorece a leitura volitiva, principalmente, quando se expressa algo irrealizável, como no exemplo:

droga é TUdo... e que:: - "ah me dá um (inint.) que num sei quê::.... e no::ssa no momento é muito bom:: num sei quê" - mas num pensa nas consequência que vai causá(r) depo::is... e acho que num deveria existí(r) isso... porque assim porque (inint.) coisa da nature::za sabe? acho que:: (tem que vê(r) o) melhor tem que sê(r) uma coisa pra::... pra nossa saúde assim uma coisa pra trazê(r) saúde que de(i)xe a gente feliz mas não só por um mome::nto que de(i)xe feliz pro resto da vida sabe? (GASPARINI-BASTOS, 2014, p. 279).

Segundo a autora, a modalidade volitiva é expressa por meio do modal dever constituindo uma perífrase de infinitivo, deveria existir. Para a autora, a leitura volitiva é favorecida em razão do emprego do futuro do pretérito (deveria), indicando que algo ainda não está realizado, e pela impossibilidade de concretização daquilo que o modal deve tomar por escopo, no caso, a inexistência de drogas, asseverado pelo advérbio de negação, num (não).

Ainda em relação à modalidade volitiva e à não controlabilidade do estado-decoisas, vejamos (3) e (4):

(3) "Daqui em diante, nos pautaremos pela vontade soberana daqueles brasileiros [...] que desejam conquistar, pelo mérito, bons empregos e sustentar com dignidade suas famílias".

(4) "Precisamos criar um ciclo virtuoso para a economia que traga a confiança necessária para permitir abrir nossos mercados para o comércio internacional, estimulando a competição, a produtividade e a eficácia, sem o viés ideológico". 
Em (3), o presidente eleito emprega o modal desejar constituindo uma perífrase com o verbo no infinitivo conquistar, ao reportar, ficando evidenciado pelo uso da terceira pessoa do plural, desejam, a volição do participante expresso (daqueles brasileiros) de obter bons empregos. Em (4), o presidente empossado faz uso do modal precisar, também constituindo uma perífrase, mas com o verbo no infinitivo criar, ao manifestar o que parece ser também um desejo seu, já que emprega o modalizador volitivo na primeira pessoa do plural, precisamos, no que se refere à criação de um círculo virtuoso para que a economia brasileira se abra ao mercado internacional. Acreditamos que, em (3) e (4), favorece uma leitura volitiva, em virtude de o participante expresso, aqueles brasileiros e nós, não possuírem o controle sobre aquilo que volicionam, pois, em (3), o participante não tem o poder necessário para controlar a demanda de bons empregos, enquanto, em (4), o participante, que inclui o presidente eleito e os demais segmentos político-econômicos brasileiros, não tem o controle sobre o mercado internacional ao ponto de permitir uma total abertura para a economia brasileira.

Em (3) e (4), podemos constatar também que o presidente eleito opta por instaurar a volição de maneira distinta, em que a natureza do enunciado modalizado indica, respectivamente, um afastamento e uma aproximação com o ouvinte. De acordo com Oliveira (2017), em (3), o presidente empossado prefere "afastar-se" do ouvinte (o que é evidenciado pelo uso da terceira pessoa do plural, desejam), preferindo reportar apenas a volição daqueles brasileiros que almejam conseguir bons empregos para sustentar de forma digna as suas famílias. Nesse sentido, a modalidade volitiva é reportativa, já que o falante apenas declara aquilo que parece ser desejável da parte de terceiros, sobre quem recai a autoridade da atitude modal. Em (4), por sua vez, o então presidente prefere aproximar-se do ouvinte (o que é evidenciado pelo uso da primeira pessoa do plural, precisamos) para manifestar o que é intencionado tanto por ele como por todos aqueles que apoiam ou integram o seu governo, em relação ao evento desejado, em questão, o crescimento da economia brasileira no mercado 
internacional. Desse modo, a modalidade volitiva é apreciativa, já que o falante faz uma apreciação sua do evento sobre o qual incide a volição, sendo ele (e aqueles que apoiam ou integram o seu governo) fonte da avaliação (apreciação) e autoridade da atitude modal.

No tocante às categorias tempo e modo, pudemos verificar que a modalidade volitiva é expressa no presente do indicativo (pretendo, querem, desejam, e precisamos), em que o tempo é relativo, já que não há uma delimitação temporal de prospecção futura, pois está localizado em um momento posterior ao da enunciação, e de aspecto irrealis, haja vista que o evento ainda não pode ser localizado no tempo e no espaço. De acordo com Felix de Oliveira (2016), a modalidade volitiva, quando instaurada no presente do indicativo, localiza a volição para o momento da enunciação, projetando o evento descrito para o futuro, configurando, dessa forma, a volição como um evento não atual e não real, relacionado-a à categoria irrealis, como no exemplo: Eu quero é fazê um negócio bem feito e tê a minha consciência tanquila, entendeu? (FELIX DE OLIVEIRA, 2016, p. 207).

O aspecto irrealis da modalidade volitiva e a prospecção futura da volição também foram empregados pelo presidente empossado por meio da perífrase ir+infinitivo, como nas ocorrências de (5) a (7):

(5) "Vamos unir o povo, valorizar a família, respeitar as religiões e nossa tradição judaico-cristã, combater a ideologia de gênero, conservando nossos valores".

(6) "Vamos honrar e valorizar aqueles que sacrificam suas vidas em nome de nossa segurança e da segurança dos nossos familiares".

(7) "Vamos valorizar o Parlamento, resgatando a legitimidade e a credibilidade do Congresso Nacional".

Em (5), (6) e (7), o presidente eleito emprega a perífrase ir+infinitivo para manifestar uma intenção (volição) não apenas sua, já que emprega, nos três casos, a primeira pessoa do plural, vamos, acerca dos eventos sobre os quais incide a volição, 
respectivamente, a união do povo brasileiro, a valorização da família, o respeito às religiões e o combate à ideologia de gênero; a valorização daqueles que garantem a segurança do povo brasileiro; e a valorização do Parlamento. Acreditamos também que a leitura volitiva nessas ocorrências se deva à não controlabilidade [- controle], por parte do participante expresso, dos estados-de-coisas sobre os quais incide a volição, com o presente do indicativo situando a volição para o momento da enunciação.

De acordo com Moreira de Oliveira (2016), a forma plena do verbo ir parte de um sentido associado a espaço físico, gramaticalizando-se ao constituir uma perífrase com um verbo no infinitivo, ir+infinitivo, passando a manifestar desejos e intenções (modalidade). Segundo o autor, o traço de modalidade, no sentido de expressar o propósito de fazer algo, permite, pois, sua gramaticalização como auxiliar de futuro, uma vez que localiza o evento para um momento posterior ao da enunciação, como no exemplo: Ele vai falar com o professor (MOREIRA DE OLIVEIRA, 2016, p. 74); que, para o autor, assinala a intenção (volição) de fazer alguma coisa, que é uma característica modal.

Segundo Felix de Oliveira (2016), a relação entre a modalidade volitiva e a noção de futuridade reside no fato de que a primeira refere-se a uma volição localizada no presente, acerca de estados-de-coisas realizáveis no futuro, imediatamente posterior ao momento da enunciação ou em um futuro mais distante. Desse modo, ainda conforme a autora, temos que a volição marca uma projeção futura da (não) realização de uma dada situação após o momento da enunciação.

\section{Considerações finais}

A investigação realizada no discurso de posse do presidente eleito, Jair Bolsonaro, foi acerca da modalidade volitiva, que, de acordo com Hengeveld e Mackenzie (2008), está relacionada ao que é (in)desejável, podendo estar orientada para o participante ou para o evento. Com base na análise empreendida, constatamos 
que a presença de modalizações relacionadas à manifestação de desejos e intenções é empregada no discurso de posse em razão de o falante (presidente eleito) expressar suas pretensões acerca de suas ações políticas como novo chefe do Poder Executivo, além de reportar, em seu discurso, o que parece ser o desejo (volição) daqueles que apoiam o seu governo, ou do que ele acredita ser o desejo das pessoas de um modo geral.

A análise do discurso de posse selecionado também revelou que parece ser mais recorrente a modalidade volitiva com orientação para o participante, visto que há uma pretensão por parte do presidente empossado, ou do participante por ele reportado, de se envolver no evento volicionado, este relacionado, geralmente, à performatização de alguma futura ação política. Nos casos analisados, a fonte da atitude modal que instaura a volição é um sujeito animado [+ humano], podendo ser especificado ou não no discurso [ \pm determinado].

A análise empreendida revelou que a leitura volitiva do enunciado modalizado é favorecida em razão da não controlabilidade [- controle] do evento sobre o qual incide a volição, que pode ser expressa por meio de verbos volitivos plenos ou por auxiliares modais (constituindo uma perífrase com verbos no infinitivo). Com relação ao tempo e ao modo verbais, a análise das ocorrências parece revelar que o presente do modo indicativo é o mais recorrente, já que este situa a volição instaurada no momento da enunciação, ainda que o evento esteja localizado em um momento posterior (futuridade).

Dessa forma, acreditamos que esta pesquisa possa de alguma forma contribuir para que surjam mais trabalhos voltados para a descrição e a análise da volição, pois, segundo Oliveira (2017), ainda se trata de uma categoria de modalidade pouco explorada, em virtude de ser delimitada, em algumas tipologias, ora como um subtipo da modalidade deôntica, ora como uma categoria acima da modalidade (a volitividade). 


\section{Referências}

DALL'AGLIO-HATTNHER, M. M. Entre o poder e o dever: fatores intervenientes na expressão da modalidade nos discursos de posse presidencial. Gragoatá (UFF), v. 25, p. 155-168, 2009. DOI https://doi.org/10.5533/1413-9073-20092709. Disponível em: https://bit.ly/2F8KILS. Acesso em: 05 jan. 2019.

FELIX DE OLIVEIRA, N. O desenvolvimento de verbos volitivos na língua portuguesa: uma abordagem construcional. 2016. 245 f. Tese (Doutorado em Linguística) - Faculdade de Letras, Universidade Federal de Juiz de Fora, Juiz de Fora, 2016. DOI https://doi.org/10.1590/s2176-6681/367313975. Disponível em: http://zip.net/bttLQZ. Acesso em: 21 dez. 2018.

GASPARINI-BASTOS, S. D. Distinções entre modalidade deôntica objetiva e subjetiva no português falado: o caso do verbo 'dever'. Confluência, v. 46, p. 273-287, 2014. DOI https://doi.org/10.18364/rc.v1i46.19. Disponível em: https://bit.ly/2LuTrTu. Acesso em: 22 dez. 2018.

HENGEVELD, K. Illocution, mood and modality. In: BOOIJ, G.; LEHMANN, C.; MUGDAN, J. (ed.). Morphology: a handbook on inflection and word formation, v. 2, p. 1190-1201, 2004.

HENGEVELD, K.; MACKENZIE, L. Functional Discourse Grammar. Oxford: Oxford University Press, 2008.

LEAL, P. M. V. Análise de Enquadramento em Discurso ou Pronunciamento Oficial: perspectivas teórico-metodológicas. Anais do XX Congresso de Ciências da Comunicação na Região Sudeste. Uberlândia: INTERCOM, p. 1-15, 2015. DOI https://doi.org/10.1590/s1809-58442013000200005. em: https://bit.ly/2QrPyzt. Acesso em: 05 jan. 2019.

MOREIRA DE OLIVEIRA, J. A trajetória da gramaticalização de ir + infinitivo em Português. Revista Guavira Letras, n. 22, p. 66-79, 2016. DOI https://doi.org/10.21747/2183-9077/rapla11. Disponível em: https://bit.ly/2ArLr11. Acesso em: 06 jan. 2019.

OLIVEIRA, A. S. Modalidade volitiva em língua espanhola nos discursos do Papa Francisco em viagem apostólica. 2017. 310 f. Dissertação (Mestrado em Linguística) Programa de Pós-Graduação em Linguística, Universidade Federal do Ceará (UFC), Fortaleza, 2017. DOI https://doi.org/10.21680/1517-7874.2018v20n2id14243. Disponível em: http://bit.ly/2odUwqY. Acesso em: 14 dez. 2017. 